\title{
IMAGENS DE MULHER E REPRESENTAÇÕES DA MODA EM VITÓRIA DA CONQUISTA - BA (1950-1965) ${ }^{1}$
}

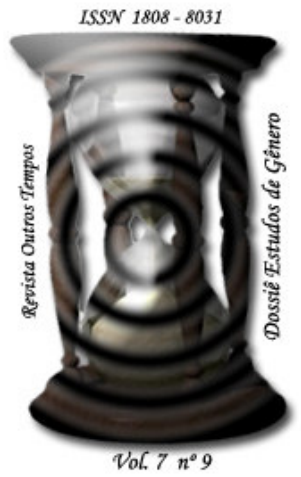

\author{
Juscelina Bárbara Anjos Matos \\ Mestre em Cultura Visual pela Universidade Federal de Goiás - UFG \\ babimatos@yahoo.com.br
}

Palavras-chave: Moda.Gênero. Identidade. Vitória da Conquista-BA.

\begin{abstract}
The aim of this article is to analyze how the clothing may reflect the complexity of gender relations and identity construction from the study of how women in Vitória da Conquista-BA was related to clothing and fashion in the 1950s.
\end{abstract}

Keywords: Fashion. Gender, Identity. Vitória da Conquista-BA.

Artigo recebido em 14/3/2010 e aprovado em 9/6/2010.

${ }^{1}$ Esse artigo é parte da minha dissertação de mestrado que tem como título "Costurando moda: uma análise das práticas vestimentares femininas em Vitória da Conquista - Ba (1950-1965)". 


\begin{abstract}
Moda e indumentária são um instrumental no processo de socialização em direção aos papéis sexuais e de gênero; elas ajudam a dar forma às idéias das pessoas sobre como homens e mulheres deveriam parecer. Não é verdade que a moda e indumentária simplesmente refletem uma identidade já existente de sexo e gênero, mas elas são "parte do processo pelo qual atitudes para com homens e mulheres, igualmente, e imagens de ambos os sexos são criadas e reproduzidas (BARNARD, 2003, p. 167).
\end{abstract}

Compreender a relação entre gênero, identidade e moda, exige antes de tudo, uma perspectiva social e histórica que torne possível analisar a importância do vestuário na formação das identidades. A história da vestimenta pode nos fornecer uma visão panorâmica de como essas relações são construídas, através dos significados que o vestuário assume ao longo do tempo e de como a cultura predominante em cada momento a influenciou. As interpretações em torno do papel social da moda revelam a variação dos códigos que ela veicula, ora indicando, por exemplo, o status, sexualidade, informando sua filiação e valores específicos de um grupo e de um tempo, ora servindo para subverter esses códigos estabelecidos.

Nesse sentido, para compreender o comportamento de moda adotado pelas mulheres de Vitória da Conquista-BA, como aqui nos interessa analisar, entre os anos de 1950 e 1965, é necessário compreender qual o papel desempenhado por essas mulheres na sociedade da época e qual a sua posição dentro da estrutura social.

Apesar de não ser nosso interesse aqui aprofundar as discussões sobre as teorias de diferenciação sexual existentes, consideramos importante a compreensão da moda como definidora de identidades de gênero para análise do tema no período proposto por esta investigação. Como afirma Crane (2006) e outros autores como Barnard (2003) e Lipovetsky (1989), só a partir dos anos 60, com a crescente influência dos estilos de rua no vestuário, que a moda emergiu como conjunto de redes que se relacionavam, diluindo as fronteiras identitárias estabelecidas até então. Até os anos 60, podemos dizer que a natureza dos estilos de moda era menos variada, e os padrões estéticos eram mais rígidos.

Desta forma, para melhor entendermos a relação da mulher com a moda, faz-se necessário tecer alguns comentários sobre o que se esperava do comportamento feminino e qual o papel social desta na década de 50, principalmente. Retomando um pouco o pensamento, como diz Bassanezi (2006), nos anos 50 os conceitos de feminino e masculino eram entendidos como inerentes à natureza do homem e da mulher. Enquanto a mulher era definida por características como pureza, docilidade, delicadeza, fragilidade, resignação e 
maternidade, o homem era reconhecido por sua força, autoridade ousadia e poder. Para a mentalidade da época, essas eram características tidas como naturais e determinavam quais os espaços onde homens e mulheres deveriam atuar. O próprio vestuário de época servia para acentuar essas diferenças. As saias amplas que, como em outras épocas, serviam para demarcar a distanciamento em relação à mulher, as cinturas bem marcadas e saltos altos que demonstravam a fragilidade e a delicadeza feminina.

"Ser mãe, esposa e dona de casa era considerado o destino natural das mulheres. $\mathrm{Na}$ ideologia dos Anos Dourados, maternidade, casamento e dedicação ao lar faziam parte da essência feminina; sem história, sem possibilidade de contestação" (BASSANEZI, 2006, p.609). Essa vocação prioritária era a marca da feminilidade da época e estava impregnada no processo de educação das mulheres. Como diz a autora, os conselhos sobre como se comportar estavam sempre presentes nas conversas entre mãe e filha, nos romances para moças, nos sermões do padre, nas opiniões de um juiz ou legislador sintonizado com seu tempo. "Isso não quer dizer que todas as mulheres pensavam e agiam de acordo com o esperado, e sim que as expectativas sociais faziam parte de sua realidade, influenciando suas atitudes e pesando em suas escolhas" (BASSANEZI, 2006, p.608).

Da mesma forma que o Brasil adotou, com algumas ressalvas, as tendências internacionais de modernização e liberação feminina, que foram impulsionadas no pós-guerra e pelo desenvolvimento econômico que incorporou a mão-de-obra feminina, o país também foi influenciado pelas campanhas estrangeiras que pregavam a volta da mulher ao lar e aos valores tradicionais da sociedade.

\section{As moças de família e a moda}

Se no Brasil, nas grandes cidades, apesar da modernização e incorporação de novos valores, a sociedade ainda mantinha um código moral bastante conservador, nas cidades menores, do interior, os padrões de comportamento eram, em alguns casos, ainda mais rígidos. Com relação à conduta feminina, esperava-se que as moças se portassem corretamente, de modo a preservar o bom nome da família para não ficarem "mal faladas".

Às moças, principalmente as da camada média da sociedade, ${ }^{2}$ era exigido um comportamento acima de qualquer suspeita. Tinham que se comportar como moças de família

\footnotetext{
${ }^{2}$ Alguns autores que discutem gênero analisam que os olhares, as cobranças recaiam com maior peso sobre as mulheres das elites e camadas médias, pois estas estavam mais em evidência. As moças mais pobres que
} 
que, segundo definição de Bassanezi (2006, p.610), eram aquelas que, "tinham gestos contidos, respeitavam os pais, preparavam-se adequadamente para o casamento, conservavam sua ignorância sexual e não se deixavam levar por intimidades físicas com os rapazes. Eram aconselhadas a se comportarem de acordo com os princípios morais aceitos pela sociedade"

No que se refere à moda, esta, como sendo um reflexo da sociedade, deveria transmitir tais valores. Se nos anos 40 a moda feminina se aproximou, de certa forma, da masculina, com formas retas, simples e, até mesmo, incorporando itens do vestuário masculino, na década seguinte a tendência era buscar transmitir as características da feminilidade, quais sejam, a delicadeza, fragilidade e, consequentemente, dependência e necessidade de proteção da mulher por parte do homem.

Em Vitória da Conquista, essa realidade não era diferente dos outros centros urbanos, como podemos perceber nos relatos das entrevistadas, mulheres que viveram sua juventude nos anos 1950. Aqui, chamamos a atenção para a metodologia adotada nesta pesquisa que está alicerçada na História Oral. Leite (2001) destaca a importância do papel da narrativa como forma de recompor o contexto do momento, de chegar ao imaginário dos sujeitos retratados. Foi só a partir das conversas travadas com diferentes atores sociais que pudemos compreender e reconstruir o contexto e práticas sociais dos sujeitos e a sua relação com a moda.

O interesse dos pesquisadores pelo estudo dos espaços privados, das práticas cotidianas fez com que se desse cada vez mais espaço à narrativa, principalmente à narrativa feminina. Por estarem mais ligadas à intimidade, era à sua memória que se recorria para focalizar o que se passou a chamar de história da vida privada. Neste sentido, as histórias de vida das mulheres participantes desta investigação ganham significado na medida em que expressam a mentalidade de uma época, de um grupo social. Como diz Meiry (2002, p.37), "algumas histórias pessoais ganham relevo na medida em que expressam situações comuns aos grupos ou sugerem aspectos importantes para o entendimento da sociedade mais ampla".

Retomando a discussão, as jovens da cidade viviam sob a vigilância constante da família e da sociedade, como forma de manter a moral e os bons costumes. Nesse sentido, o vestuário era um dos elementos utilizados para se identificar uma mulher de bem. Roupas mais ousadas, decotadas, mostrando mais do que era permitido na época, podiam caracterizar uma jovem como moça leviana. Em relação às casadas, os códigos vestimentares eram ainda mais rígidos. Como diz Bassanesi (2006, p. 612), “ficava mal à reputação de uma jovem, por exemplo, usar roupas muito ousadas, sensuais". Nos relatos que se seguem podemos perceber 
como a moda estava intimamente ligada à imagem da mulher e daquilo que se esperava do seu comportamento.

Losa Tavares $^{3}$ relata, com sua linguagem pitoresca que optamos por transcrever de forma literal, a reação do pai quando ela usou um vestido de alça e que mostrava parte das costas:

\begin{abstract}
Eu tinha uma roupa que quando eu vesti o meu pai me disse que eu estava nua. Uma pessoa que estava em Salvador, foi pra lá estudar, quando chegava trazia aquelas novidades. Eu vi a pessoa na rua e mandei a costureira fazer um vestido igual para mim. Uma roupa estampadinha, de cambraia de linho. Bem linda a roupa! Não lembro se a saia era franzida ou pregueada, mas tenho impressão que era pregueadinha. Era uma roupa bem festa mesmo, aqui tinha uma alcinha e as costas nuas com a alcinha, atrás vinha uma capinha que abotoava na alça. Ela ficava solta atrás e quando o vento batia dava pra ver as costas. Quando eu vesti essa roupa e meu pai viu, disse: - volta e tira essa roupa, você está nua! Pensa bem, disse que eu estava nua. Hoje, eu nem sei como é que é. Aí eu gravei essa roupa, eu tenho essa roupa na mente $[\ldots]$.
\end{abstract}

E continua,

Sim, eu fui para o internato, meu pai resolveu morar na roça e a gente ficou aqui num internato. Aí quando eu cheguei na casa de D. Cotinha com essas roupas, eu disse: agora já posso vestir minhas roupas porque meu pai está na roça e eu estou aqui, eu visto minha roupa na hora que eu quiser. E D. Cotinha era como se fosse um pensionato de freira. Aí quando meu pai foi me matricular lá, que a gente ficou 3 anos lá, a primeira coisa que ela disse foi eu não gosto que ninguém vista shortinho curtinho e nem que ande nua aqui no pensionato, porque aqui é misto, homem e mulher, e eu não quero que ninguém ande nua aqui.

Um dia a gente estava arrumando pra sair, ia para a matinée porque no cinema ela não deixava a gente ir não, era de $3 \mathrm{~h}$ às $6 \mathrm{~h}$ da tarde, e a gente estava arrumando quando D. Cotinha me viu com essa mesma roupa que o meu pai viu. Ela disse: você esta pensando que vai sair com essa roupa? Não vai não, aqui não anda nua assim não. Ôh menina, você está toda nua aqui atrás. Vai trocar e coloca essa roupa no fundo da mala, você não vai vestir mais aqui. Pronto, eu não vesti mais essa roupa. Quando eu ia fazer roupa não fazia mais assim, fazia de manguinha, mais decente porque ela não deixava usar.

Losa Tavares copiou o modelo de vestido de uma jovem que morava em Salvador, onde, provavelmente, já havia uma liberdade maior com relação ao vestuário feminino, por receber com mais rapidez as notícias do mundo da moda e pela própria característica de cidade litorânea, onde as pessoas acabam mostrando mais o corpo.

Com relação aos acessórios, Marisa Correia ${ }^{4}$ lembra de um modelo de sandália que se usava na época, a gueixa, uma sandália estilo havaianas e que foi incorporado como item de moda pelas jovens, apesar de não ser muito bem vista.

[...] Aí as mocinhas de família, as mocinhas mais socialites usaram essa sandália como sapato de moda. Só que na época não era muito bem visto a sandália sem

\footnotetext{
${ }^{3}$ Entrevista concedida em 21 de janeiro de 2008.

${ }^{4}$ Entrevista concedida em 23 de janeiro de 2008.
} 
traseira. As sandálias altas sem traseira só quem usava eram as mulheres de vida livre. As mulheres mais ligadas à família, da sociedade, usavam sempre uma sandália abotoada. O calcanhar de fora do mesmo jeito, mas tinha a traseira do calcanhar e o abotoamento. Essa sandália era comum, se usava além do sapato fechado, alto ou baixo, se usava assim. Mas as sandálias eram abotoadas, não era de calcanhar livre.

Essa sandália de calcanhar livre começou a ser usada nos anos 60, como moda, mas era uma moda meio libertina, meu pai mesmo criticava, falava: mulher minha não bota essa sandália.

Tentando explicar a má fama da sandália de "calcanhar livre”, Marisa Correia diz que talvez seja uma herança cultural, já que este era um modelo que estava ligado à imagem das escravas ao longo da história.

Era um modelo até interessante inclusive porque era um modelo que as baianas de acarajé, do candomblé usavam. As escravas no século XVIII e XIX usavam aquela sandalinha. Você pega reproduções de Debret ou de outros artistas, aí você vai ver a freqüência dessa sandalinha, que era dedicada às escravas, ex-escravas. Por isso, era um sapato mal afamado, porque não era um sapato de dama fina, era um sapato de mulher meio desqualificada, depois virou moda.

Quando não estavam perto da família, as moças ousavam mais no vestuário, aderindo às novas modas lançadas no mercado. Losa Tavares refere-se a isso:

Eu me lembro de uma vez, quando eu trabalhava no banco, e fui passar umas férias em Salvador e lá eu vi um maiô. Eu não tinha comprado o meu maiô porque deixei pra comprar lá, naquela época tava começando a usar 'engana mamãe'. Quando eu vi, eu era toda vaidosa, eu falei: eu vou comprar é esse. E a minha irmã falou: - você compra, mas se tirar foto não mostra para o meu pai não, ele vai te dar uma bronca dizendo que você estava aqui ficando nua. Mas eu achei lindo, fui para a praia, chamei a atenção. Eu era magrinha das pernas grossas. Aí chegou um rapaz tirando foto e eu tirei. No outro dia tirei também, tirei umas 3 fotos de binóculo, porque quando eu vi os retratos achei bonito e tirei mais. E eu chego de Salvador, a gente mostrando as coisas - eu era muito displicente e deixei os binóculos em cima da mesa -, meu pai pegou e olhou. Sabe o que ele fez? Quebrou e jogou fora. Ainda bem que foi só um, ficaram dois.

Mesmo nos uniformes escolares, que eram símbolo de disciplinarização do corpo, pois exigiam um cuidado maior, um gestual mais contido, as jovens buscavam marcar sua individualidade costumizando a roupa de acordo com seu gosto.

É, a gente dobrava o cós curto. Padre Palmeira (diretor do Colégio) não admitia saia curta, as saias cobriam os joelhos. E a meia era comprida. Horrorosa, a gente pegava e dobrava, fazia ela soquete. Dobrava, dobrava, dobrava. Quando a gente chegava perto do Ginásio subia, para entrar de meia comprida. ${ }^{5}$

\footnotetext{
${ }^{5}$ Entrevista com Celeste Rosa, concedida em 26 de janeiro de 2008.
} 
Ao relembrar do uniforme de Educação Física, Celeste comenta do tamanho do short que segundo ela era "curtinho". "É, a gente subia. Ninguém era besta”. O short contava com um elástico para permitir que as moças tivessem uma maior mobilidade nas aulas de Educação Física e nos jogos. Como podemos observar, mesmo num período em que as cobranças com relação ao comportamento feminino eram grandes, as jovens sempre achavam uma forma de marcar sua individualidade. Como dizem Crane (2006) e Barnard (2003), nesse caso a moda tanto servia para marcar a identidade de gênero como para subvertê-la.

\section{Identidade Alternativa ${ }^{6}$ : incorporando elementos do vestuário masculino}

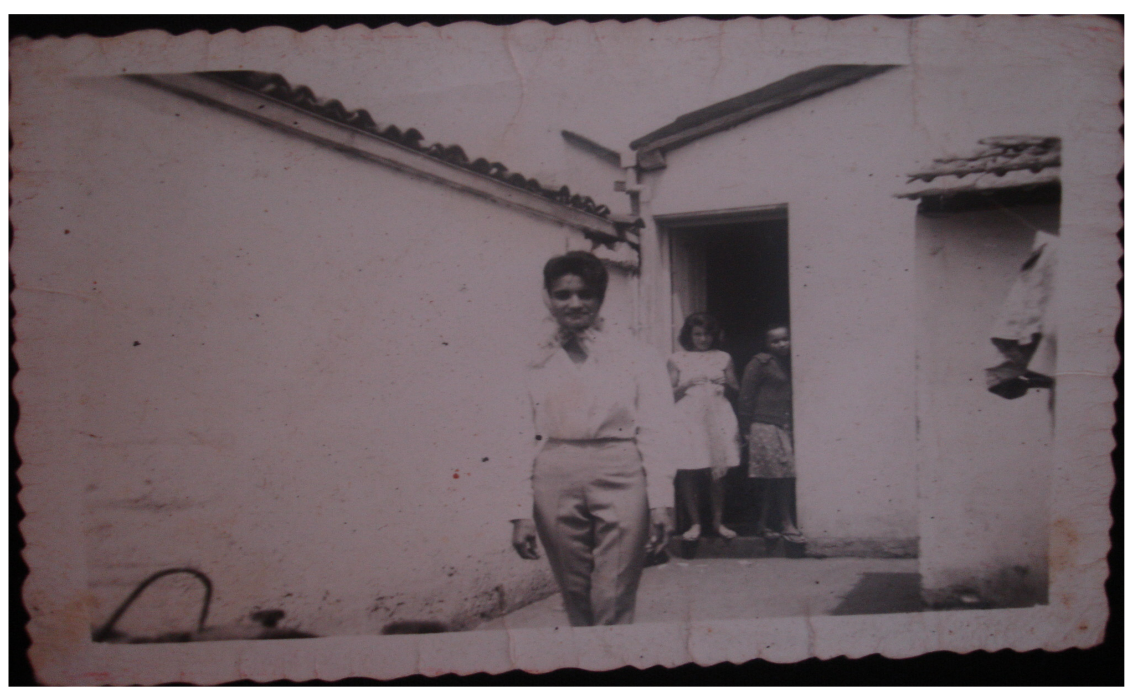

Figura 1 - Maria Macedo saindo de casa para viajar, 1960.

Acervo de família Maria Macedo

A imagem de Maria Macedo, trajando calça comprida e blusa de corte masculino destoa completamente da visão, no imaginário coletivo, sobre qual seria o lugar e o papel social que cabia à mulher nos anos 50. Ao olhar pela primeira vez tal imagem, muitas questões vieram à tona e levaram ao pensamento que mesmo num período em que se consideravam as fronteiras simbólicas de gênero e classe social mais rígida, era possível que membros desses grupos sociais buscassem subverter a ordem estabelecida, buscando demarcar a sua individualidade através de escolhas diferenciadas do vestuário. Retornando à observação da imagem que apresentamos, nos questionamos sobre qual o lugar dessa figura de mulher que não se encaixava nos padrões estéticos da época amplamente aceitos. A calça

\footnotetext{
${ }^{6} \mathrm{O}$ estilo alternativo foi termo utilizado por Crane (2006) e pode ser compreendido como um conjunto de sinais, extraídos do vestuário masculino, composto de itens usados separadamente ou em conjunto, que modificam sutilmente o efeito do traje feminino. O estilo originou na França no século XIX, mas a influência inglesa sobre o estilo foi inconfundível como afirma autora. Aqui usamos o termo para falar da incorporação de itens do vestuário masculino pelas mulheres em meados do século XX.
} 
era um item do vestuário masculino, e raramente se viam mulheres fazendo uso indiscriminado dessa peça, principalmente, numa época em que se apregoava o culto à feminilidade.

\begin{abstract}
Durante a década de 30, na França, as mulheres ricas usavam calças em balneários, mas raramente o faziam na cidade. As normas que regiam a indumentária correta nas ruas eram rígidas. Historiografias orais sugerem que não era correto sair sem chapéu, luvas e meias, mesmo no verão. Não se encontravam mulheres de calças nas ruas. Durante a Segunda Guerra Mundial, as calças foram usadas com frequiência devido à escassez de toda espécie de roupas novas, mas somente na metade da década de 1950 é que passaram a ser aceitáveis para a vida urbana (CRANE, 2006, p.257).
\end{abstract}

E continua Crane (2006, p.257):

$\mathrm{Na}$ Inglaterra, o uso das calças, tanto para o trabalho quanto para o lazer, foi apressado pela Segunda Guerra Mundial. [...] As calças foram aceitas pelas mulheres de classe operária durante a guerra, e apenas muito mais tarde, na década de 60, pelas de classe média, depois de aparecerem nas coleções de estilistas franceses.

No Brasil, essas mudanças da moda chegavam principalmente pelo cinema e revistas importadas. Mas as novas tendências eram absorvidas com moderação. Não era comum ver mulheres trajando calças, a não ser como uniforme de trabalho. O uso dessas peças era mais reservado aos espaços de lazer, sendo diluído com mais facilidade nas camadas jovens, onde o gosto pela novidade era crescente.

Se pensarmos numa realidade do interior do país, em que os valores tradicionais imperavam, a calça como elemento do guarda-roupa feminino custou a ser aceita, como demonstram as narrativas. Celeste Rosa diz que passou a usar calça comprida já nos anos 60 e destaca a contrariedade do filho, 'ainda um bebê', ao vê-la usando um traje ainda tão marcado como vestuário masculino:

Aqui, eu me lembro do meu filho, o chilique que Leonardo deu. Ele era menino pequeno, 2 anos, e eu deixei ele na casa de minha mãe e ele deu um chilique porque eu estava de calça comprida, ia viajar com William. Com ciúme, um filho de 2 anos: tira, tira. E William: - deixa de ser besta moleque. Ele falava: -Mainha esta de calça comprida. Usar calça comprida e fumar. Fumar tinha que ser escondido dele. Eu nunca vi uma criança de 2 anos com cabeça de velho e é até hoje.

Celeste destaca também a aceitação do uso da calça nos espaços de trabalho:

Eu me lembro que o prefeito Orlando Leite foi o primeiro prefeito que aceitou que as funcionárias usassem calça comprida no trabalho. Eu me lembro que Vani chegou e disse: - Celeste, minha filha, pode vir de calça. Porque não podia. O prefeito que 
autorizou o uso pelas funcionárias e nós fizemos uma farda pra usar. Calça comprida era só para viagem, para montar a cavalo, num pasto, numa fazenda. Não era do uso diário não, de jeito nenhum. Morria de frio, porque não podia usar e aqui era frio.

Dinah Cajaíba ${ }^{7}$, em seu depoimento, também relata que não era comum ver mulheres usando calça naquela época. Segundo ela, calça só era aceitável em espaços e momentos restritos como o Carnaval e durante a Exposição Agropecuária que acontecia na cidade. Era o momento em que se podia usar roupas mais confortáveis.

As narrativas mencionadas acima corroboram com as análises de Crane (2006) que afirma que "essas mudanças nas normas do vestuário foram primeiramente exploradas em espaços públicos isolados ligados ao lazer e nos locais de trabalho das mulheres de classe operária”. Aqui vale ressaltar que as depoentes, que pertenciam às camadas com menor poder aquisitivo da sociedade conquistense, eram trabalhadoras o que explica, na concepção da autora, a aceitação mais fácil da calça como item do seu guarda-roupa.

Como afirma Crane (2006, p. 198), as roupas e as escolhas do vestuário constituem campos valiosos para examinar as relações entre os discursos marginais e hegemônicos. "Embora as histórias do vestuário elegante dêem a impressão de consenso, a moda na verdade envolve um alto grau de debate e controvérsia".

Retomando a imagem apresentada, podemos dizer, da mesma forma, que o uso da calça e camisa de corte masculino por Maria Macedo pode estar relacionado ao fato de esta não fazer parte das camadas médias e altas da sociedade conquistense onde, segundo teóricos da moda, a cobrança pelo uso das tendências e as fronteiras simbólicas entre de gênero são mais rígidas. A possibilidade de romper com os padrões estéticos era maior para as mulheres de classe mais baixa onde, como diz Bourdieu (2007), o que imperava era a cultura da necessidade. Na moda isso significava um vestuário prático, funcional e durável.

Outro fato que pode explicar a adoção de elementos do vestuário masculino para compor seu visual pode ser o fato de D. Maria trabalhar desde que chegou a Vitória da Conquista, em meados dos anos 50, numa fábrica de roupas masculinas. A proximidade com esse tipo de vestuário pode ter facilitado a incorporação dessas peças no seu cotidiano. Nesse caso, o uso da calça não era tomado como uma forma de contestação, simplesmente fazia parte da sua vida.

Ainda podemos especular que o fato de ser uma mulher financeiramente independente e que gostava de viajar, como ela mesma relata, contribuía para que estivesse em contato mais direto com as transformações sociais e absorvesse com mais facilidade as mudanças. D. Maria

\footnotetext{
${ }^{7}$ Entrevista concedida em 02 de dezembro de 2008.
} 
costumava ir com certa frequência ao Rio de Janeiro e chegou até a morar algum tempo por lá. Como diz Crane (2006, p. 33), "à medida que as redes sociais do indivíduo se expandem, ou que seus contatos se tornam variados, ele é exposto a novas formas de cultura e torna-se propenso a adotá-las".

Como podemos perceber, as roupas constituem indicadores sutis de como são vivenciados as diferentes posições dentro de uma sociedade. $\mathrm{O}$ vestuário pode ser visto como um importante reservatório de significados passíveis de ser manipulados e reconstruídos e acentuar identidades pessoais. Para além de serem usadas para revelar identidades de classe e gênero, as mensagens transmitidas pelas roupas referem-se, fundamentalmente, a como homens e mulheres que consideram seus papéis de gênero e esperam que os outros os percebam. 


\section{Referências}

\section{Fontes}

CAJAÍBA, Dinah. Depoimento. [02/12/2008]. Vitória da Conquista. Entrevista concedida a Juscelina Bárbara A. Matos.

CORREIA, Marisa Correia. Depoimento. [23/01/2008]. Vitória da Conquista. Entrevista concedida a Juscelina Bárbara A. Matos.

MACEDO, Maria. Depoimento. [19/01/2008]. Vitória da Conquista. Entrevista concedida a Juscelina Bárbara A. Matos.

ROSA, Maria Celeste. Depoimento [26/01/2008]. Vitória da Conquista. Entrevista concedida a Juscelina Bárbara A. Matos.

TAVARES, Losa. Depoimento [21/01/2008]. Vitória da Conquista. Entrevista concedida a Juscelina Bárbara A. Matos.

\section{Bibliografia}

BARNARD, Malcolm. Moda e Comunicação. Tradução: Lúcia Olinto. Rio de Janeiro: Rocco, 2003.

BASSANEZI, Carla. Mulheres dos anos dourados. PRIORI,Mary Del (org). História das mulheres no Brasil. $8^{a}$ Ed. São Paulo: Contexto, 2006. p. 607-639.

BAUDELAIRE, Charles. Sobre a modernidade: o pintor da vida moderna. (org. Teixeira Coelho). Rio de Janeiro: Paz e Terra, 1996.

BOURDIEU, Pierre. A distinção: crítica social do julgamento. Tradução: Daniela Kern; Guilherme J. F. Teixeira. São Paulo: Edusp; Porto Alegre: Zouk. 2007.

CRANE, Diana. A moda e o seu papel social: classe, gênero e identidade das roupas. Tradução: Cristiana Coimbra. São Paulo: Editora Senac São Paulo, 2006.

LEITE, Miriam Moreira. Retratos de família: leitura da fotografia histórica. São Paulo: Ed. Da Universidade de São Paulo, 2001. (Texto e Arte; 9)

LIPOVETSY, Gilles. Império do efêmero: a moda e seus destinos nas sociedades modernas. Tradução: Maria Lúcia Machado. 2 ed. São Paulo: Companhia das Letras, 1989.

LUCENA, Paola Lili. Discutindo intimidades: percepções sobre a sexualidade feminina no jornal Lar Católico. In: XIII Encontro Nacional da Anpuh-Rio, XIII 2008. Rio de Janeiro. Anais... Rio de Janeiro: Anpuh, 2008. Disponível em: http://www.encontro2008.rj.anpuh.org/resources/content/anais/1212965565_ARQUIVO_Disc utindointimidades - OVERDADEIRO(1).pdf. Acesso em: 08/10/2008. 
MATOS, Juscelina Bárbara A. Costurando moda: uma análise das práticas vestimentares femininas em Vitória da Conquista-Ba (1950-1965). Dissertação de Mestrado, Pós-Graduação em Cultura Visual - Universidade Federal de Goiás, 2009.

MEIHY, José Carlos Sebe Bom. Manual de história oral. 4 ed. São Paulo: Edições Loyola, 2002. 